\title{
ANALISIS KLAUSULA KONTRAK YANG TERKAIT DENGAN KLAIM PADA FIDIC CONDITION OF CONTRACT 1999
}

\author{
Eduardus Gerald ${ }^{1}$ dan Sarwono Hardjomuljadi ${ }^{2}$ \\ ${ }^{1}$ Jurusan Teknik Sipil, Universitas Tarumanegara Jakarta \\ Email: eduard.gerald@gmail.com \\ ${ }^{2}$ Program Studi Teknik Sipil, Universitas Mercu Buana \\ Email: sarwonohm2@yahoo.co.id
}

Masuk: 25-06-2021, revisi: 24-09-2021, diterima untuk diterbitkan: 06-10-2021

\begin{abstract}
ABSTRAK
Kontrak konstruksi digunakan dalam semua pekerjaan konstruksi. Indonesia telah memasuki zaman pembangunan dimana kegiatan pembangunan infrastruktur semakin meningkat. Pembangunan yang terus meningkat menarik investor asing untuk datang dan menjalin hubungan kerja sama. Perjanjian kontrak yang digunakan tentu berstandar internasional, salah satunya FIDIC. Akan tetapi sering terjadi klaim yang berujung sengketa ketika menggunakan standar kontrak tersebut. Maka dari itu dibutuhkan penelitian yang membahas klausula didalam FIDIC Red Book 1999 yang terkait dengan klaim oleh kontraktor, dan perlu diketahui juga klausula yang menyebabkan sengketa di Indonesia dalam kontrak FIDIC. Penelitian dilakukan menggunakan sumber data primer yang berasal dari survei dengan kuesioner dan sumber data sekunder yang berasal dari keputusan pengadilan. Kuesioner dalam penelitian ini terdiri dari 23 butir pertanyaan dan menggunakan skala Likert 5. Data diolah dengan metode analisis faktor untuk menentukan faktor dominan penyebab klaim. Pengolahan data dilakukan dengan bantuan softtware SPSS v26.0, dan didapatkan 7 klausula dominan penyebab klaim kontraktor pada FIDIC Red Book yaitu: 1) 8.4 Perpanjangan Waktu Penyelesaian; 2) 11.8 Penyelidikan oleh Kontraktor; 3) 17.1 Pemberian Ganti Rugi; 3 ) 7.4 Pengujian; 4) 8.9 Konsekuensi Penghentian; 5) 14.8 Keterlambatan Pembayaran; dan 7) 4.12 Kondisi Fisik yang Tidak Dapat Diperkirakan Sebelumnya. Dari data sekunder ditemukan Klausula penyebab sengketa dalam kontrak FIDIC Red Book tahun 1999 di Indonesia adalah: 1) 2.1 Hak untuk Memasuki Lapangan; 2) 4.10 Data Lapangan; 3) 4.12 Kondisi Fisik yang Tidak Dapat Diperkirakan Sebelumnya; 4) 8.2 Waktu Penyelesaian; 5) 8.4 Perpanjangan Waktu Penyelesaian; dan 6) 8.7 Denda Keterlambatan.
\end{abstract}

Kata Kunci: analisis faktor; klaim Kontraktor; kontrak konstruksi; FIDIC Red Book

\begin{abstract}
Construction contracts are used in all construction works. Indonesia has entered an era of development where infrastructure development activities are increasing. The ever-increasing development attracts foreign investors to come and establish cooperative relationships. The contract agreements used are international contracts, one of which is FIDIC. However, there are often claims that lead to disputes when using this condition of contract. Therefore, research is needed to identify the clauses in the FIDIC Red Book 1999 which are related to claims by contractors, and it is also necessary to know the clauses that cause disputes in Indonesia due to FIDIC contracts. The study was conducted using primary data sources derived from surveis with questionnaires and secondary data sources derived from court decisions. The questionnaire in this study consisted of 23 questions and used a Likert scale 5 . The data was processed by factor analysis method to determine the dominant factor causing the claim. Data processing was carried out with the help of SPSS v26.0 software, and produced 7 dominant clauses causing contractor claims in the FIDIC Red Book, namely: 1) 8.4 Extension of Time for Completion; 2) 11.8 Contractor to Search; 3$) 17.1$ Indemnities; 3) 7.4 Testing; 4) 8.9 Consequences of Suspension; 5) 14.8 Delayed Payment; and 7) 4.12 Unforeseeable Physical Conditions. Frome the secondary data found the clauses causing disputes in Indonesia due to FIDIC contract were found namely: 1) 2.1 Right of Access to the Site; 2) 4.10 Site Data; 3) 4.12 Unforeseeable Physical Conditions; 4) 8.2 Time for Completion; 5) 8.4 Extension of Time for Completion; and 6) 8.7 Delay Damages.
\end{abstract}

Keywords: factor analysis; Contractor claims; construction contracts; FIDIC Red Book 


\section{PENDAHULUAN}

\section{Latar Belakang}

Indonesia masuk dalam kategori negara berkembang, yang artinya negara yang sedang giatgiatnya melakukan pertumbuhan ekonomi. Pertumbuhan ekonomi ini tercermin pada Anggaran Pendapatan dan Belanja Negara Indonesia dari tahun ke tahun yang terus meningkat, khususnya dalam bidang infrastruktur. Hal ini dapat dilihat dari APBN tahun 2016-2020, yang terus meningkat. APBN bidang infrastruktur yang terus meningkat menandakan bahwa jumlah pekerjaan konstruksi semakin berkembang.

"Dalam penyelenggaraan jasa konstruksi, kontrak antara Pengguna Jasa dan Kontraktor merupakan bagian paling penting untuk kedua belah pihak agar menjadi perhatian khusus"(Wibisono \& Hardjomuljadi, 2017). untuk memastikan keberlangsungan proyek konstruksi, dibutuhkan yang namanya suatu perjanjian atau kontrak. Kontrak konstruksi adalah salah satu jaminan untuk memastikan keberhasilan proyek (Arief \& Hardjomuljadi, 2020).

Pada era globalisasi ini, standar kontrak konstruksi internasional yang paling banyak digunakan di Indonesia adalah kontrak FIDIC. Hal ini diakibatkan karena standar kontrak FIDIC merupakan standar yang sudah diakui secara internasional, dan juga direkomendasikan oleh institusi internasional seperti World Bank Group, International Bank for Reconstruction and Development, International Development Association, Japan International Cooperation Agency, ILO dan lain sebagainya. Kontrak FIDIC yang sering digunakan pada proyek konstruksi di Indonesia adalah FIDIC Condition of Contract for Construction atau dikenal dengan Red Book dan FIDIC Design Build yang dikenal dengan Yellow Book. Akan tetapi pekerjaan kontstruksi yang menggunakan kontrak FIDIC sering mengalami klaim. "Hal ini disebabkan oleh terjadinya perbedaan interpretasi atau pemaknaan pada klausula-klausula yang sudah tertulis di dalam kontrak ataupun perbedaan pemahaman pada isi dari kontrak kerja yang sudah disepakati bersama"(Kapuasiana \& Hardjomuljadi, 2020). Pemahaman mengenai kontrak FIDIC sangat dibutuhkan untuk menghindari kesalapahaman yang berpotensi sengketa. Ditambah lagi semakin banyak proyek konstruksi asing, yang masuk ke Indonesia, mewajibkan untuk menggunakan standar kontrak FIDIC. "Mitigasi terjadinya sengketa hukum dengan tindakan preventif sebelum terjadi perikatan kontrak yaitu dengan menghilangkan penyebab sengketa"(Djatnika, 2018). Karena itulah penelitian mengenai klausula kontrak yang dapat menyebabkan klaim pada FIDIC Condition of Contract for Construction harus dilakukan sebagai upaya mitigasi agar tidak terjadinya sengketa konstruksi.

\section{Rumusan Masalah}

permasalahan yang akan dibahas pada penelitian ini adalah mengidentifikasi klausula-klausula yang terkait klaim oleh Kontraktor pada standar kontrak FIDIC, melakukan analisis faktor berdasarkan jawaban responden dari hasil survei dengan kuesioner. Pembahasan klausulaklausula yang terkait klaim di Indonesia juga diperlukan untuk meminimalisi terjadinya klaim kedepannya. Tujuan dari penelitian ini adalah sebagai berikut: 1) Mengidentifikasi klausula penyebab klaim pada FIDIC Condition of Contract for Construction tahun 1999; 2) Mengetahui penyebab terjadinya sengketa pada kontrak FIDIC di Indonesia.

\section{Manfaat Penelitian}

Adapun manfaat dari penelitian ini adalah sebagai berikut: 1) Memberikan informasi mengenai klausula-klausula pada standar kontrak FIDIC yang terkait klaim oleh Kontraktor pada pelaksanaan proyek konstruksi; 2) Memberikan masukan bagi Kontraktor dan Pengguna Jasa untuk melakukan tindakan yang diperlukan terkait klausula yang dapat memberikan dampak 
negatif pada pelaksanaan proyek konstruksi; 3) Memberikan suatu kajian ilmiah serta menjadi pedoman atau bahan penelitian selanjutnya.

\section{METODE PENELITIAN}

Penelitian ini dilakukan dengan metode campuran kualitatif dan kuantitatif yang bertujuan untuk mendapatkan opini dari responden mengenai klausula-klausula pada kontrak FIDIC Red Book 1999 yang terkait dengan klaim oleh kontrakor, dan mengetahui penyebab sengketa kontrak FIDIC di Indonesia.

\section{Jenis Penelitian}

Metode yang digunakan adalah metode campuran kualitatif dan kuantitatif yang bertujuan untuk mendapatkan opini dari responden mengenai klausula-klausula pada kontrak FIDIC Red Book 1999 yang terkait dengan klaim oleh kontrakor, dan mengetahui penyebab sengketa kontrak FIDIC di Indonesia.

\section{Populasi dan Sampel}

Populasi adalah keseluruhan dari objek yang akan diteliti di dalam penelitian. Sampel adalah bagian dari populasi yang hendak diteliti dan jumlahnya lebih sedikit dari populasi. Populasi penelitian ini adalah para pengguna kontrak FIDIC Red Book 1999 yang sedang dalam tahap pelaksanaan konstruksi, maupun yang telah selesai.

Sampel dalam penelitian ini diambil dengan menggunakan teknik purposive sampling, yaitu pengambilan sampel berdasarkan kriteria agar sampel yang diambil sesuai dengan tujuan penelitian. Sampel dalam penelitian ini adalah: Kontraktor, penyedia jasa, dan konsultan Enjinir, yang pernah menggunakan kontrak FIDIC Red Book 1999.

Pengumpulan data dalam penelitian ini dilakukan sebagai berikut: 1)Data Primer merupakan data yang secara langsung diambil dari objek penelitian. Data primer penelitian ini merupakan hasil dari kuesioner yang didapatkan dari para pengguna kontrak FIDIC; 2) Data Sekunder merupakan data yang diperoleh dari hasil studi literatur seperti jurnal, buku, putusan Pengadilan, dan penelitian lain terkait dengan penelitian ini.

\section{Instrumen Penelitian}

Instrumen yang digunakan dalam penelitian ini berupa kuesioner dengan penentuan variabel berdasarkan studi literatur dari beberapa penelitian yang dilakukan oleh: 1) Ediyanto Arief dan Sarwono Hardjomuljadi (2020); 2) Galih Adya Taurano dan Sarwono Hardjomuljadi (2013); 3) Kenny Kapuasiana dan Sarwono Hardjomuljadi (2017); 4) Randy Angga Erland Kesek dan Sarwono Hardjomuljadi (2020); 5) Sarwono Hardjomuljadi (2014); 6) Sigit Ari Wibawa dan Mayun Nadiasa, I Gst. Ketut Sudipta (2016). Setelah itu kuesioner divalidasi oleh 7 orang pakar dengan total 23 butir pertanyaan. Kuesioner disebarkan dengan cara menggunakan google form yang tautannya dikirimkan kepada para responden dengan Linkedin atau Whatsapp. Skala frekuensi yang digunakan dalam penelitian ini adalah skala Likert dengan skala 5.

\section{HASIL DAN PEMBAHASAN Profil Responden}

Data hasil survei berjumlah 32 dengan mayoritas responden bekerja sebagai Kontraktor (41\%), Pengguna Jasa (37\%), dan Konsultan Enjinir (22\%). Tingkat pendidikan responden S1 sebesar $60 \%$, S2 sebesar 34\%, S3 sebesar 6\%. Pengalaman bekerja Responden yang kurang dari 5 tahun memiliki persentase sebesar 14\%; 5-10 tahun sebesar 21\%; 10-15 tahun sebesar 10\%; 15-20 tahun sebesar 17\%; dan lebih dari 20 tahun sebesar $38 \%$. 


\section{Uji Persyaratan Instrumen}

Pengujian persyaratan instrumen dilakukan untuk mengetahui apakah instrumen penelitian, dalam penelitian ini berupa kuesioner, layak digunakan untuk mengumpulkan data. Pengujian yang dilakukan adalah uji validitas dan uji reliabilitas dengan derajat signifikansi sebesar $95 \%$ atau alpha $=0,05$. Pengujian dilakukan dengan bantuan software Statistical Product and Service Solutions Versi 26. Kedua uji tersebut memerlukan nilai $\mathrm{r}$ yang didapat dengan melihat tabel $\mathrm{r}$. Dari Tabel $r$ dengan $n=32$ didapatkan nilai $r$ sebesar 0,3494 , yang kemudian digunakan untuk pengujian. Dari 23 butir pernyataan, didapatkan 22 yang lolos uji validitas, hasil pengujian dapat dilihat pada Tabel 1.

Tabel 1. Hasil Uji Validitas

\begin{tabular}{|c|c|c|c|}
\hline Variabel & Nilai r & Sig. & Kriteria \\
\hline $\mathrm{X} 1$ & $0.372^{*}$ & 0.036 & Valid \\
\hline $\mathrm{X} 2$ & $0.542^{* *}$ & 0.001 & Valid \\
\hline $\mathrm{X} 3$ & $0.468^{* *}$ & 0.007 & Valid \\
\hline $\mathrm{X} 4$ & $0.646^{* *}$ & 0.000 & Valid \\
\hline $\mathrm{X} 5$ & $0.672^{* *}$ & 0.000 & Valid \\
\hline X6 & $0.680^{* *}$ & 0.000 & Valid \\
\hline $\mathrm{X} 7$ & $0.500^{* *}$ & 0.004 & Valid \\
\hline $\mathrm{X} 8$ & $0.667^{* *}$ & 0.000 & Valid \\
\hline X9 & $0.757^{* *}$ & 0.000 & Valid \\
\hline $\mathrm{X} 10$ & $0.405^{*}$ & 0.021 & Valid \\
\hline $\mathrm{X} 11$ & $0.593^{* *}$ & 0.000 & Valid \\
\hline $\mathrm{X} 12$ & $0.703^{* *}$ & 0.000 & Valid \\
\hline $\mathrm{X} 13$ & $0.737^{* *}$ & 0.000 & Valid \\
\hline $\mathrm{X} 14$ & $0.768^{* *}$ & 0.000 & Valid \\
\hline $\mathrm{X} 15$ & $0.533^{* *}$ & 0.002 & Valid \\
\hline $\mathrm{X} 16$ & $0.476^{* *}$ & 0.006 & Valid \\
\hline $\mathrm{X} 17$ & 0.297 & 0.099 & Tidak valid \\
\hline $\mathrm{X} 18$ & $0.582^{* *}$ & 0.000 & Valid \\
\hline X19 & $0.696^{* *}$ & 0.000 & Valid \\
\hline $\mathrm{X} 20$ & $0.713^{* *}$ & 0.000 & Valid \\
\hline $\mathrm{X} 21$ & $0.655^{* *}$ & 0.000 & Valid \\
\hline $\mathrm{X} 22$ & $0.682^{* *}$ & 0.000 & Valid \\
\hline $\mathrm{X} 23$ & $0.719^{* *}$ & 0.000 & Valid \\
\hline \multicolumn{4}{|c|}{ *Korelasi signifikan dalam level 0,05} \\
\hline
\end{tabular}

Hasil uji reliabilitas menghasilkan nilai Alpha Cronbach's 0.922, lebih besar daripada r Tabel maka instrumen penelitian dinyatakan memiliki reliabilitas tinggi. 


\section{Uji Persyaratan Analisis Data}

Dalam melakukan analisis faktor ada beberapa persyaratan yang harus dipenuhi, yaitu: 1) Data harus terdistribusi normal; 2) Nilai Kaiser-Mayer-Olkin Measure of Sampling Adequacy (KMO MSA) lebih besar dari 0,5 dan nilai Bartlett's Test of Sphericity (Sig.) lebih kecil dari 0,05;3) Ada hubungan atau korelasi yang kuat antar variabel. Hal ini dapat dilihat pada nilai Anti-image Correlation antar variabel lebih besar dari 0,5. Setelah ketigany terpenuhi maka analisis faktor dapat dilakukan.

Uji Normalitas dilakukan dengan metode Kolmogorov-Smirnov One Sample Test, dengan $\alpha=$ 0,05 . Hasil pengujian didapatkan signifikansi sebesar 0,200 lebih besar dari nilai signifikansi $\alpha=$ 0,05 sehingga dapat disimpulkan variabel penelitian terdistribusi normal. Hasil pengujian dapat dilihat pada Tabel 2.

Tabel 2. Hasil uji normalitas

\begin{tabular}{|c|c|c|}
\hline $\mathrm{N}$ & & 32 \\
\hline \multirow{2}{*}{$\begin{array}{l}\text { Normal } \\
\text { Parameters }\end{array}$} & Mean & 67.34 \\
\hline & Std. Deviation & 15.601 \\
\hline \multirow{3}{*}{$\begin{array}{l}\text { Most Extreme } \\
\text { Differences }\end{array}$} & Absolute & 0.097 \\
\hline & Positive & 0.051 \\
\hline & Negative & -0.097 \\
\hline Test Statistic & & 0.097 \\
\hline $\begin{array}{l}\text { Asymp. Sig. (2- } \\
\text { tailed) }\end{array}$ & & $.200^{\mathrm{c}, \mathrm{d}}$ \\
\hline
\end{tabular}

Syarat selanjutnya adalah nilai KMO MSA lebih besar dari 0,5 dan nilai signifikansi Bartlett's lebih kecil dari 0,05. Hasil uji KMO MSA dan Bartlett's dapat dilihat pada Tabel 3.

Tabel 3. Uji KMO MSA dan Bartlett's

Kaiser-Meyer-Olkin Measure of

0.551

Sampling Adequacy.

\begin{tabular}{llr}
\hline Bartlett's Test of Sphericity & $\begin{array}{l}\text { Approx. Chi- } \\
\text { Square }\end{array}$ & 553.491 \\
\hline & df & 231 \\
\hline Sig. & 0.000
\end{tabular}

Nilai KMO MSA sebesar 0,551 lebih besar dari 0,5 dan nilai signifikansi Bartlett's (Sig.) lebih kecil dari 0,000 yang berarti dibawah 0,05 maka dinyatakan lolos persyaratan uji analisis faktor. Syarat selanjutnya adalah dengan melihat anti image matrices dengan nilai MSA setpai variabel harus diatas 0,5. Apabila ada yang dibawah 0,5 variabel dapat dibuang dan pengujian dilakukan kembali. Dari uji anti image matrices pertama ditemukan variabel X1, X16, X18, dan X20 tidak memenuhi syarat maka variabel tersebut dikeluarkan. Dari pengujian kedua ditemukan variabel $\mathrm{X} 2$, X3, dan X7 tidak memenuhi syarat maka variabel tersebut dikeluarkan. Dari pengujian ketiga didapatkan semua variabel memenuhi syarat sehingga analisis faktor dapat dilanjutkan. Hasil uji anti image matrices ketiga dapat dilihat pada Tabel 4. 
Tabel 4. Hasil uji anti image matrices ketiga

\begin{tabular}{|c|c|c|c|c|c|c|c|c|c|c|c|c|c|c|c|}
\hline \multicolumn{16}{|c|}{ Anti-image Matrices } \\
\hline & & $\mathrm{X} 4$ & $\mathrm{X} 5$ & $\mathrm{X} 8$ & $\mathrm{X} 9$ & $\mathrm{X} 10$ & $\mathrm{X} 11$ & $\mathrm{X} 12$ & $\mathrm{X} 13$ & $\mathrm{X} 14$ & $\mathrm{X} 15$ & $\mathrm{X} 19$ & $\mathrm{X} 21$ & $\mathrm{X} 22$ & $\mathrm{X} 23$ \\
\hline \multirow{14}{*}{$\begin{array}{l}\text { Anti-image } \\
\text { Covariance }\end{array}$} & $\mathrm{X} 4$ & 0.426 & -0.008 & -0.033 & 0.052 & 0.138 & -0.063 & -0.086 & -0.034 & -0.002 & -0.016 & -0.095 & -0.068 & 0.048 & -0.019 \\
\hline & $\mathrm{X} 5$ & -0.008 & 0.289 & -0.115 & 0.076 & -0.013 & -0.026 & 0.047 & -0.044 & 0.013 & -0.128 & -0.077 & 0.063 & -0.044 & -0.111 \\
\hline & $\mathrm{X} 8$ & -0.033 & -0.115 & 0.283 & -0.087 & 0.039 & -0.025 & 0.019 & -0.003 & -0.016 & -0.051 & -0.048 & -0.032 & 0.046 & -0.018 \\
\hline & $\mathrm{X9}$ & 0.052 & 0.076 & -0.087 & 0.239 & 0.034 & 0.086 & -0.073 & -0.030 & 0.011 & -0.086 & -0.133 & -0.021 & -0.010 & -0.039 \\
\hline & $\mathrm{X} 10$ & 0.138 & -0.013 & 0.039 & 0.034 & 0.198 & -0.094 & -0.075 & -0.095 & 0.084 & 0.052 & -0.070 & -0.021 & 0.048 & -0.053 \\
\hline & $\mathrm{X} 11$ & -0.063 & -0.026 & -0.025 & 0.086 & -0.094 & 0.314 & -0.071 & 0.073 & -0.045 & -0.096 & -0.059 & 0.058 & -0.093 & 0.048 \\
\hline & $\mathrm{X} 12$ & -0.086 & 0.047 & 0.019 & -0.073 & -0.075 & -0.071 & 0.163 & -0.035 & -0.011 & -0.062 & 0.089 & 0.003 & 0.012 & -0.080 \\
\hline & X13 & -0.034 & -0.044 & -0.003 & -0.030 & -0.095 & 0.073 & -0.035 & 0.191 & -0.137 & 0.000 & 0.005 & 0.037 & -0.071 & 0.085 \\
\hline & $\mathrm{X} 14$ & -0.002 & 0.013 & -0.016 & 0.011 & 0.084 & -0.045 & -0.011 & -0.137 & 0.304 & 0.018 & -0.021 & -0.018 & 0.005 & -0.074 \\
\hline & $\mathrm{X} 15$ & -0.016 & -0.128 & -0.051 & -0.086 & 0.052 & -0.096 & -0.062 & 0.000 & 0.018 & 0.442 & 0.095 & -0.034 & 0.032 & 0.124 \\
\hline & X19 & -0.095 & -0.077 & -0.048 & -0.133 & -0.070 & -0.059 & 0.089 & 0.005 & -0.021 & 0.095 & 0.314 & 0.020 & -0.010 & -0.004 \\
\hline & $\mathrm{X} 21$ & -0.068 & 0.063 & -0.032 & -0.021 & -0.021 & 0.058 & 0.003 & 0.037 & -0.018 & -0.034 & 0.020 & 0.210 & -0.151 & -0.054 \\
\hline & $\mathrm{X} 22$ & 0.048 & -0.044 & 0.046 & -0.010 & 0.048 & -0.093 & 0.012 & -0.071 & 0.005 & 0.032 & -0.010 & -0.151 & 0.189 & 0.000 \\
\hline & $\mathrm{X} 23$ & -0.019 & -0.111 & -0.018 & -0.039 & -0.053 & 0.048 & -0.080 & 0.085 & -0.074 & 0.124 & -0.004 & -0.054 & 0.000 & 0.287 \\
\hline \multirow{14}{*}{$\begin{array}{l}\text { Anti-image } \\
\text { Correlation }\end{array}$} & $\mathrm{X} 4$ & $.786^{\mathrm{a}}$ & -0.022 & -0.096 & 0.162 & 0.476 & -0.172 & -0.327 & -0.120 & -0.007 & -0.037 & -0.259 & -0.226 & 0.168 & -0.055 \\
\hline & $\mathrm{X} 5$ & -0.022 & $.751^{\mathrm{a}}$ & -0.401 & 0.289 & -0.056 & -0.086 & 0.218 & -0.189 & 0.042 & -0.358 & -0.256 & 0.256 & -0.187 & -0.385 \\
\hline & $\mathrm{X} 8$ & -0.096 & -0.401 & $.860^{\mathrm{a}}$ & -0.335 & 0.165 & -0.085 & 0.088 & -0.011 & -0.054 & -0.145 & -0.162 & -0.132 & 0.198 & -0.064 \\
\hline & X9 & 0.162 & 0.289 & -0.335 & $.785^{\mathrm{a}}$ & 0.156 & 0.312 & -0.370 & -0.140 & 0.040 & -0.266 & -0.485 & -0.092 & -0.047 & -0.150 \\
\hline & $\mathrm{X} 10$ & 0.476 & -0.056 & 0.165 & 0.156 & $.558^{\mathrm{a}}$ & -0.377 & -0.418 & -0.486 & 0.343 & 0.175 & -0.279 & -0.103 & 0.246 & -0.221 \\
\hline & $\mathrm{X} 11$ & -0.172 & -0.086 & -0.085 & 0.312 & -0.377 & $.709^{\mathrm{a}}$ & -0.312 & 0.297 & -0.145 & -0.258 & -0.187 & 0.225 & -0.381 & 0.160 \\
\hline & $\mathrm{X} 12$ & -0.327 & 0.218 & 0.088 & -0.370 & -0.418 & -0.312 & $.756^{\mathrm{a}}$ & -0.197 & -0.050 & -0.229 & 0.391 & 0.016 & 0.067 & -0.370 \\
\hline & $\mathrm{X} 13$ & -0.120 & -0.189 & -0.011 & -0.140 & -0.486 & 0.297 & -0.197 & $.754^{\mathrm{a}}$ & -0.570 & 0.000 & 0.020 & 0.185 & -0.376 & 0.364 \\
\hline & $\mathrm{X} 14$ & -0.007 & 0.042 & -0.054 & 0.040 & 0.343 & -0.145 & -0.050 & -0.570 & $.854^{\mathrm{a}}$ & 0.049 & -0.069 & -0.073 & 0.020 & -0.251 \\
\hline & $\mathrm{X} 15$ & -0.037 & -0.358 & -0.145 & -0.266 & 0.175 & -0.258 & -0.229 & 0.000 & 0.049 & $.708^{\mathrm{a}}$ & 0.254 & -0.112 & 0.110 & 0.347 \\
\hline & X19 & -0.259 & -0.256 & -0.162 & -0.485 & -0.279 & -0.187 & 0.391 & 0.020 & -0.069 & 0.254 & $.762^{\mathrm{a}}$ & 0.080 & -0.040 & -0.013 \\
\hline & $\mathrm{X} 21$ & -0.226 & 0.256 & -0.132 & -0.092 & -0.103 & 0.225 & 0.016 & 0.185 & -0.073 & -0.112 & 0.080 & $.736^{\mathrm{a}}$ & -0.759 & -0.220 \\
\hline & $\mathrm{X} 22$ & 0.168 & -0.187 & 0.198 & -0.047 & 0.246 & -0.381 & 0.067 & -0.376 & 0.020 & 0.110 & -0.040 & -0.759 & $.735^{\mathrm{a}}$ & -0.002 \\
\hline & $\mathrm{X} 23$ & -0.055 & -0.385 & -0.064 & -0.150 & -0.221 & 0.160 & -0.370 & 0.364 & -0.251 & 0.347 & -0.013 & -0.220 & -0.002 & $.791^{\mathrm{a}}$ \\
\hline
\end{tabular}

\section{Analisis Faktor}

Analisis faktor dilakukan terhadap data yang telah lolos uji persyaratan instrumen dan uji persyaratan analisis data. Jumlah data yang dianalisis sebanyak 32 data dan 14 variabel. Hasil analisis dapat dilihat pada Tabel 5. communalities.

Tabel 5. communalities

Klausula

Initial

\begin{tabular}{|c|c|c|}
\hline Klausula & Initial & Extraction \\
\hline $\begin{array}{l}\text { 8.4 Perpanjangan Waktu } \\
\text { Penyelesaian }\end{array}$ & 1.000 & 0.908 \\
\hline 11.8 Penyelidikan oleh Kontraktor & 1.000 & 0.853 \\
\hline 17.1 Pemberian Ganti Rugi & 1.000 & 0.842 \\
\hline 7.4 Pengujian & 1.000 & 0.832 \\
\hline 8.9 Konsekuensi Penghentian & 1.000 & 0.831 \\
\hline 14.8 Keterlambatan Pembayaran & 1.000 & 0.818 \\
\hline $\begin{array}{l}\text { 4.12 Kondisi Fisik yang Tidak Dapat } \\
\text { Diperkirakan Sebelumnya }\end{array}$ & 1.000 & 0.778 \\
\hline $\begin{array}{l}\text { 8.5 Keterlambatan Akibat Tindakan } \\
\text { Penguasa }\end{array}$ & 1.000 & 0.743 \\
\hline 17.4 Konsekuensi dari Risiko & 1.000 & 0.731 \\
\hline $\begin{array}{l}\text { 10.2 Serah Terima Sebagian } \\
\text { Pekerjaan }\end{array}$ & 1.000 & 0.716 \\
\hline 19.4 Konsekuensi Keadaan Kahar & 1.000 & 0.673 \\
\hline 8.1 Tanggal Mulai Pekerjaan & 1.000 & 0.666 \\
\hline $\begin{array}{l}10.3 \text { Gangguan terhadap Pengujian } \\
\text { pada Penyelesaian }\end{array}$ & 1.000 & 0.660 \\
\hline 4.7 Pemasangan Tanda-tanda Batas & 1.000 & 0.618 \\
\hline
\end{tabular}


Tabel communalities digunakan untuk mengetahui seberapa besar sebuah variabel dapat menjelaskan faktor. Nilai Extraction klausula 8.4 Perpanjangan Waktu Penyelesaian $=0.908$. Ini artinya Penyebab Klaim dapat diwakili variabel klausula 8.4 Perpanjangan Waktu Penyelesaian sebesar 90,8\% begitu pula dengan klausula lainnya. Nilai rata -ata dari semua Extraction adalah 0,762, maka nilai Extraction yang diatas nilai rata-rata menjadi klausula dominan penyebab klaim kontraktor pada FIDIC Red Book 1999.

\section{Sengketa di Indonesia}

Untuk mengetahui klausula penyebab sengketa di Indonesia dilakukan analisis kualitatif terhadap putusan pengadilan. Dari 18 putusan pengadilan mengenai sengketa kontrak FIDIC, 8 diantaranya adalah standar kontrak FIDIC Red Book, yang dikelompokan menjadi 4 kasus sengketa.

Tabel 6. Kasus Pertama

Proyek

Pihak

Putusan

Pekerjaan Tanjung

Priok Access Road

Construction (Phase 2)

Package 4, Section NS

Link dengan Nomor Kontrak

KU.08.08/PJATPPLN/

NS/XII/2010-1

tertanggal 23 Desember 2010 ,

Nilai kontrak :

Tidak diketahui
Arbitrase

Nomor 557/XII/ARB-BANI/2013

13 Februari 2013
SMCC-Hutama Joint

Operation

(Perusahaan Asing

(Jepang) dengan PT

Hutama Karya

(Persero))
Majelis Arbiter mengabulkan tuntutan/klaim atas:

1. Ganti rugi kepada Pemohon sebesar

Rp. 35.562.098.332,- dan ¥

132.425.156,

2. Bunga atas keterlambatan

pembayaran sebesar Rp.

2.582.116.433,-

\begin{tabular}{|c|c|c|}
\hline Pemohon & Termohon & \\
\hline \multicolumn{2}{|c|}{$\begin{array}{c}\text { Pengadilan Negeri } \\
\text { Nomor 209/Pdt.G/2015/PN. Jkt. Sel. } \\
21 \text { Mei } 2015\end{array}$} & \multirow{3}{*}{$\begin{array}{l}\text { 1. Menolak Gugatan Penggugat untuk } \\
\text { seluruhnya; } \\
\text { 2. Menghukum Penggugat untuk } \\
\text { membayar biaya perkara sebesar } \\
\text { Rp. } 316.000,-\end{array}$} \\
\hline $\begin{array}{l}\text { Direktorat Jendral } \\
\text { Bina Marga, } \\
\text { Kementerian PUPR }\end{array}$ & $\begin{array}{c}\text { SMCC-Hutama Joint } \\
\text { Operation (Perusahaan } \\
\text { Asing (Jepang) dengan } \\
\text { PT Hutama Karya } \\
\text { (Persero)) }\end{array}$ & \\
\hline Pengugat & Tergugat & \\
\hline
\end{tabular}

Pengadilan Tinggi

Nomor 104 B/Pdt.Sus-Arbt/2019

21 Oktober 2015

1. Menyatakan gugatan Penggugat tidak dapat diterima

2. Menghukum Pemohon dahulu

SMCC-Hutama Joint

Direktorat Jendral Operation (Perusahaan

Bina Marga,

Kementerian PUPR

Asing (Jepang) dengan

Penggugat untuk membayar biaya

perkara ditetapkan sebesar

PT Hutama Karya

Rp500.000,00 (lima ratus ribu rupiah)

Pemohon

Termohon 
Tabel 7. Rangkuman kasus Kedua

Proyek

Pihak

Putusan

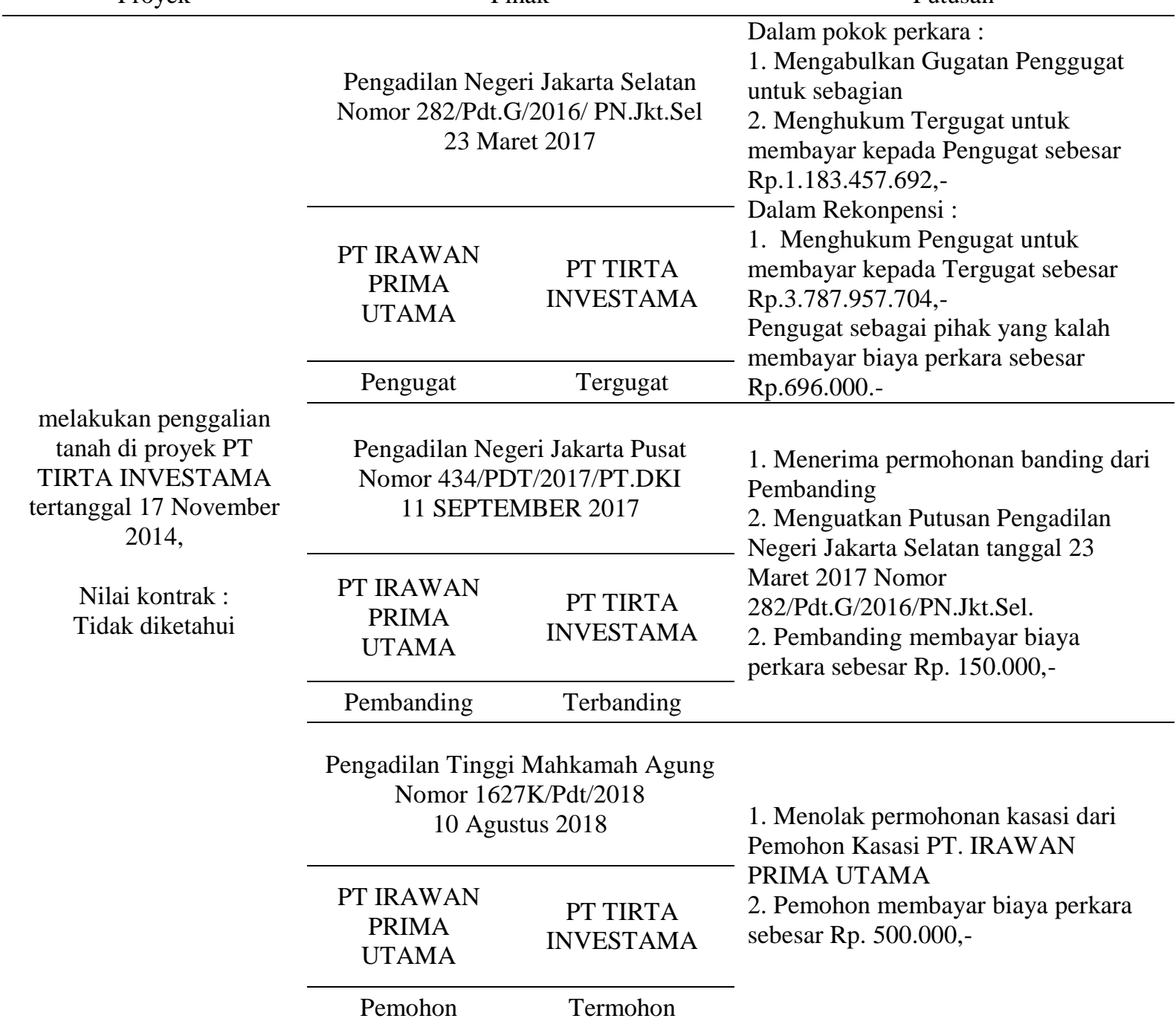

Dari kasus tersebut ditemukan 6 klausula yang menjadi penyebab sengketa. Hasil analisis dapat dilihat pada Tabel 11.

Tabel 8. Klausula yang terkait sengketa

\begin{tabular}{|c|c|c|}
\hline Kasus & klaim Kontraktor & Klaim Pengguna Jasa \\
\hline 1 & $\begin{array}{l}\text { 8.4 Perpanjangan Waktu } \\
\text { Penyelesaian }\end{array}$ & - \\
\hline 2 & $\begin{array}{l}\text { 2.1 Hak untuk Memasuki } \\
\text { Lapangan dan } \\
\text { 8.4 Perpanjangan Waktu } \\
\text { Penyelesaian }\end{array}$ & - \\
\hline 3 & $\begin{array}{c}\text { 4.10 Data Lapangan dan } 4.12 \\
\text { Kondisi Fisik yang Tidak Dapat } \\
\text { Diperkirakan Sebelumnya }\end{array}$ & $\begin{array}{l}\text { 8.7 Denda Keterlambatan dan } \\
\text { 8.2 Waktu Penyelesaian }\end{array}$ \\
\hline & - & $\begin{array}{l}\text { 8.7 Denda Keterlambatan dan } \\
\text { 8.2 Waktu Penyelesaian }\end{array}$ \\
\hline
\end{tabular}


Penentuan klausula yang dibahas dari hasil analisis apa yang menjadi klausula dominan penyebab klaim.

\section{Klausula 8.4 Perpanjangan Waktu Penyelesaian}

Klausula 8.4 Perpanjangan Waktu Penyelesaian merupakan klausula paling dominan yang terkait dengan klaim oleh Kontraktor. Klausula ini berkaitan dengan aspek yang sangat penting dalam proyek, yaitu waktu. Perpanjangan Waktu Penyelesaian merupakan hal yang terjadi hampir di semua proyek konstruksi.

Cara kontraktor menyampaikan klaim sudah diatur dalam Klausula 20.1 Klaim Kontraktor. Ketika menentukan perpanjangan waktu berdasarkan Sub-Klausula 20.1, Enjinir harus meninjau penetapan sebelumnya dan boleh menambah tetapi tidak boleh mengurangi perpanjangan waktu secara keseluruhan. Menurut Sarwono Hardjomuljadi (2014) penyebab terjadinya klaim ini adalah "inefficiency and disruption" atas kegiatan kontraktor akibat pihak lain. Ketidak efisien dan gangguan ini berasal dari banyak sumber, maka dari itu hal tersebut sering terjadi di dalam proyek. Klausula ini menjadi penyebab dominan klaim karena Kontraktor pasti akan melakukan klaim Perpanjangan Waktu Penyelesaian apabila penyebab ketidak efisien dan gangguan bukan berasal dari Kontraktor.

\section{Klausula 11.8 Penyelidikan oleh Kontraktor}

Penyelidikan dalam sebuah proyek penting dilakukan untuk menemukan penyebab dan solusi dari sebuah masalah. Dalam Klausula ini disebutkan "Kontraktor harus, apabila diminta oleh Enjinir, menyelidiki penyebab cacat mutu, berdasarkan pengarahan dari Enjinir. Kecuali apabila kerusakan harus diperbaiki atas biaya kontraktor berdasarkan Sub-Klausula 11.2 Biaya Perbaikan cacat Mutu, Biaya penyelidikan ditambah keuntungan yang wajar harus disepakati atau ditetapkan oleh Enjinir berdasarkan Sub-Klausula 3.5 Penentapan dan harus ditambahkan ke dalam Harga Kontrak." Karena perintah penyelidikan diberikan oleh Enjinir, maka kontraktor berhak untuk melakukan klaim atas biaya yang dikeluarkan dan keuntungan dari jasa penyelidikan yang telah dilakukan. Dalam klausula ini jelas terteta bahwa kontraktor sebagai pihak yang dimintai jasa nya sehingga harus dibayarkan atas jasa yang telah diberikan. Setiap kali ada perintah penyelidikan, Kontraktor harus melakukannya dan otomatis Kontraktor menginginkan imbalan atas jasa nya. Maka dari itu klausula ini menjadi klausula dominan penyebab klaim.

\section{Klausula 17.1 Pemberian Ganti Rugi}

Klausula 17.1 Pemberian Ganti Rugi mengatur mengenai ganti rugi kedua belah pihak, Kontraktor terhadap Pengguna Jasa, dan Pengguna Jasa terhadap Kontraktor. Dikutip dari liputan6.com "Merujuk pada data BPJS Ketenagakerjaan tahun 2019 terdapat 114.000 kasus kecelakaan kerja, tahun 2020 terjadi peningkatan pada rentang Januari hingga Oktober 2020 BPJS Ketenagakerjaan mencatat terdapat 177.000 kasus kecelakaan kerja," kata Menaker dalam Peringatan Bulan K3 Nasional di Kilometer Nol Sabang, Selasa (12/12/2021). Lanjutnya, jika angka tersebut dihitung berdasarkan jumlah klaim yang diajukan oleh pekerja yang mengalami kecelakaan kerja, artinya angka kecelakaan kerja yang sesungguhnya jauh lebih besar, karena belum semua tenaga kerja menjadi peserta BPJS Ketenagakerjaan. Sehingga, berdasarkan data tersebut, semua dituntut untuk lebih serius dalam menerapkan budaya K3 (Keselamatan dan Kesehatan Kerja)" Kecelakaan kerja timbul dari berbagai macam faktor, apabila faktor tersebut bukan berasal dari Kontraktor, otomatis Kontraktor akan mengajukan klaim atas kerugian yang diterima nya. Semakin banyak kejadian kecelakaan kerja maka klaim ganti rugi akan semakin banyak juga. 


\section{Klausula 7.4 Pengujian}

Keterlambatan dalam pengujian bisa disebabkan oleh ketidakhadiran Pengguna Jasa ketika akan dilaksanakan pengujian dan Pengguna Jasa mengatakan pengujian tidak boleh dilakukan tanpa Pengguna Jasa. Maka dari itu Pengujian terpaksa harus ditunda. Penundaan dapat mengakibatkan keterlambatan dan pengeluaran biaya untuk persiapan pengujian selanjutnya, terlebih lagi ketika pekerjaan tidak dapat dilanjutkan sebelum lulus pengujijan. Penyebab kerugian yang bukan berasal dari Kontraktor menjadi dasar yang kuat untuk mengajukan klaim. Ditambah lagi di dalam klausula tersebut dinyatakan "Kontraktor harus menyampaikan pemberitahuan" yang berarti Kontraktor wajib melakukan klaim, maka setiap terjadi kerugian akibat pengujian akan dilakukan klaim.

\section{Klausula 8.9 Konsekuensi Penghentian}

Tidak jarang dalam kegiatan konstuksi terjadi penghentian kegiatan. Penghentian kegiatan akan berakibat terlambatnya waktu penyelesaian, dan memungkinkan untuk terjadinya kehilangan keuntungan Kontraktor sesuai rencana awal kontrak. Terlebih lagi disebutkan bahwa Kontraktor harus menyapaikan pemberitahuan kepada Enjinir, yang berarti klaim dalam klausula ini merupakan tugas Kontraktor.

\section{Klausula 14.8 Keterlambatan Pembayaran}

Dalam kontrak FIDIC Red Book pembayaran dilakukan dalam beberapa tahap, yaitu pembayan uang muka, pembayaran per termin progres, dan pembayaran akhir. Uang muka yang diterima oleh Kontraktor biasa digunakan untuk melaksanakan kegiatan konstruksi, begitu pula dengan uang pembayaran per termin progres. Akibat yang timbul atas keterlambatan pembayaran adalah perencanaan Kontraktor menjadi tidak sesuai dan dapat menyebabkan kerugian, ditambah lagi untuk melanjutkan pekerjaan dibutuhkan biaya yang rencananya berasal dari pembayaran Pengguna Jasa tersebut sehingga memungkinkan terjadinya keterlambatan pekerjaan akibat pembayaran yang tidak tepat waktu.

\section{Klausula 4.12 Kondisi Fisik yang Tidak Dapat Diperkirakan Sebelumnya}

Klasusula ini telah mengatur tindakan apa yang harus dilakukan Enjinir ketika Kontraktor melakukan klaim, tertera jelas bahwa Enjinir juga harus menyelidiki dan menginspeksi kondisi fisik yang dilaporkan tersebut lalu membertikan keputusan berupa penetapan apakah kondisi ini tidak dapat atau dapat diperkirakan sebelumnya. Klausula ini juga digunakan sebagai dasar klaim pada kasus 3 dimana keadaan fisik di bawah permukaan tanah tidak dapat diperkirakan sebelumnya dari data pengujian tanah yang diberikan.

\section{KESIMPULAN DAN SARAN}

\section{Kesimpulan}

Berdasarkan temuan dan analisis yang telah dilakukan pada bab sebelumnya, didapatkan kesimpulan sebagai berikut:

a. Ditemukan 14 Klausula yang teridentifikasi terkait dengan klaim oleh kontraktor pada FIDIC Condition of Contract for Construction tahun 1999;

b. Dari 14 Klausula yang teridentifikasi, didapatkan Klausula dominan penyebab klaim adalah: a) Klausula 8.4 Perpanjangan Waktu Penyelesaian (90,8\%); b) Klausula 11.8 Penyelidikan 
oleh Kontraktor (85,3\%); c) Klausula 17.1 Pemberian Ganti Rugi $(84,2 \%)$; d) Klausula 7.4 Pengujian (83,2\%); e) Klausula 8.9 Konsekuensi Penghentian (83,1\%); f) Klausula 14.8 Keterlambatan Pembayaran (81,8\%); g) Klausula 4.12 Kondisi Fisik yang Tidak Dapat Diperkirakan Sebelumnya (77,8\%); dan

c. Klausula penyebab sengketa dalam kontrak FIDIC Red Book di Indonesia adalah: a) Klausula 2.1 Hak untuk Memasuki Lapangan; b) Klausula 4.10 Data Lapangan; c) Klausula 4.12 Kondisi Fisik yang Tidak Dapat Diperkirakan Sebelumnya; d) Klausula 8.2 Waktu Penyelesaian; e) Klausula 8.4 Perpanjangan Waktu Penyelesaian; dan f) Klausula 8.7 Denda Keterlambatan.

\section{Saran}

Berdasarkan penelitian yang telah dilakukan, didapatkan beberapa saran yaitu:

a. Analisis klausula penyebab sengketa dalam standar kontrak FIDIC Red Book tahun 1999 di Indonesia dapat dikembangkan dengan menganalisis data sengketa arbitrase dari BANI karena kebanykan proyek dengan kontrak FIDIC menyelesaikan sengketa dengan arbitrase atau dewan sengketa.

b. Dapat dilakukan penelitian lebih lanjut untuk jenis standar kontrak FIDIC lainnya seperti Yellow Book, Pink Book, dan standar kontrak internasional lainnya yang kedepannya akan digunakan di Indonesia.

c. Penelitian selanjutnya dapat menganalisis klausul-klausul terkait klaim dari sudut pandang Pengguna Jasa.

\section{REFERENSI}

Arief, E., \& Hardjomuljadi, S. (2020). Analisis Perbandingan Model Kontrak Apbn Dan Apbd Terhadap Model Kontrak Fidic. Konstruksia, 11(2), 8.

Djatnika, S. S. (2018). MITIGASI SENGKETA HUKUM DALAM KONTRAK KERJA KONSTRUKSI. Institut Arbiter Indonesia.

Erland Kesek, R. A., \& Hardjomuljadi, S. (2020). Analisis Red Clause Kontrak Konstruksi APBD Dengan Fidic Red Book 1999. Konstruksia, I(2), 103-126.

Hardjoluljadi, S, dkk. (2008). Persyaratan Kontrak Untuk Pelaksanaan Konstruksi (diterjemahkan kedalam bahasa Indonesia). Jakarta: Lembaga Pengembangan Jasa Konstruksi.

Hardjomuljadi, S. (2014). Pengantar Kontrak Konstruksi FIDIC Conditions of Contract Buku Kesatu. Bandung: Logoz Publishing.

Hardjomuljadi, S. (2014). Factor Analysis on Causal of Construction Claims and Disputes in Indonesia. International Journal of Applied Engineering Research, 9(22), 12421-12446.

Jumlah Kecelakaan Kerja Meningkat di 2020, Capai 177.000 Kasus. 2021. Santia, Tiara. Jakarta. Tersedia di https://www.liputan6.com/bisnis/read/4454961/ jumlah-kecelakaan-kerjameningkat-di-2020-capai-177000-kasus diakses pada 2 Juni 2012 pukul 09.30 WIB.

Kapuasiana, K., \& Hardjomuljadi, S. (2020). Analisis Faktor Penyebab Klaim Pada Fidic Design Build 2017. Konstruksia, 11(1), 11-32.

Mahkamah Agung, Putusan Nomor 104 B/Pdt.Sus-Arbt/2019.

Mahkamah Agung, Putusan Nomor 1627 K/Pdt/2018.

Pengadilan Negeri Jakarta Pusat, Putusan Nomor 434/PDT/2017/PT.DKI

Pengadilan Negeri Jakarta Selatan, Putusan Nomor 209/Pdt.G/2015/PN. Jkt. Sel.

Pengadilan Negeri Jakarta Selatan, Putusan Nomor 282/Pdt.G/2016/PN.Jkt.Sel. 
Taurano, G. A., Hardjomuljadi, S. (2013). Analisis Faktor Penyebab Klaim pada Proyek Konstruksi yang Menggunakan FIDIC Conditions of Contract for Plant and Design Build. Konstruksia 5 (1), 14-25.

Wibawa, Sigit, Ari, Mayun Nadiasa, I Gst. Ketut S. (2016). Analisis Faktor-Faktor Penyebab Terjadinya Klaim dalam Pelaksanaan Proyek Konstruksi Bangunan Gedung di Kota Denpasar. Jurnal Ilmiah Teknik Sipil 2(22), 95-102.

Wibisono, A., \& Hardjomuljadi, S. (2017). Analisis Pemilihan Model Kontrak Fidic Rainbow Contract 2017 Pekerjaan Pembangunan Dermaga. 2017, 15-24. 